\section{The Power of}

\section{Community Impact}

\section{How Brownsville, Brooklyn, is Making a Difference in Early Literacy}

KRISTEN ROCHAALDOCLCH

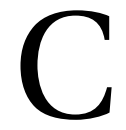

ollective Impact groups focus on bringing different sectors-nonprofits, government organizations, and for-profit companies-together in one neighborhood, city, or community.

The phrase Collective Impact (CI) was officially first mentioned in a 2011 article titled "Collective Impact" in the Stanford Social Innovation Review, and it quickly rose to be one of the most popular philanthropic ideas in the years following. It was also identified by the White House Council for Community Solutions, created by President Barack Obama in 2010 , as an important framework for progress on social issues.

Today, CI may not be one of the most popular buzz terms, but the model itself is still very much alive and continues to impact social change across the country.

CI coalitions take on a variety of forms; however, each CI group focuses on collaborative leadership, with the belief that when different stakeholders in one community create common goals to solve the social issues facing their community, they will create lasting solutions welcomed by those impacted. Traditionally, the people brought together to lead CI alliances are community leaders from organizations such as literacy coalitions, hospitals, clinics, public schools, childcare centers, city councils, social agencies, and public libraries. However, there is a crucial group of people missing from this list—community members.

After working in programming at a public library, it seems unthinkable to plan improvements to a program or space without consulting the people who use the space daily and attend the programs. Libraries do not tell patrons what they

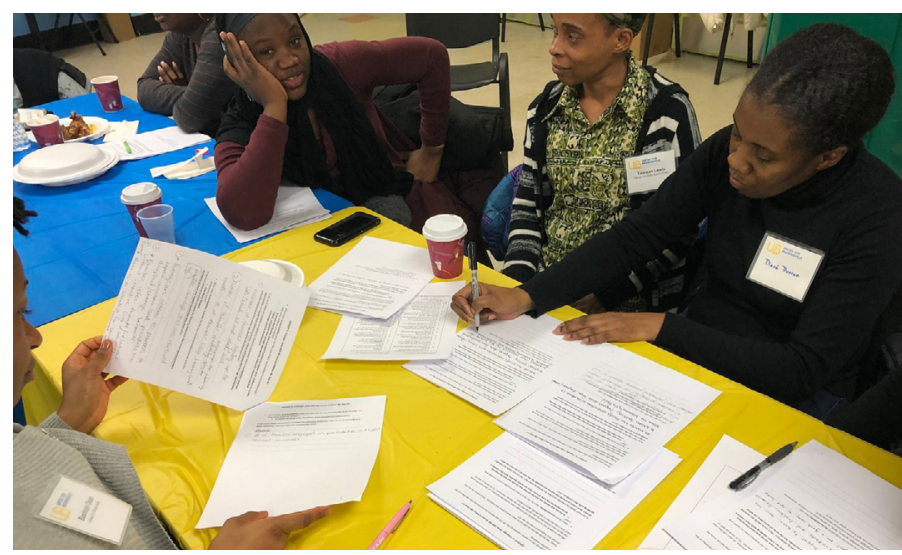

FAB members weigh in on what they would like to see covered in the Family Co-Op curriculum, as well as what they would like to celebrate about Brownsville.

want; instead, they engage their patrons to learn what they need from their library and then create programs and spaces based on their feedback. Community engagement is one of the areas public libraries excel in.

New York City is home to several CI efforts with an exemplary example being United for Brownsville (UB), a nonprofit and CI organization based in Brooklyn. UB describes itself as a "collaborative of families and professionals who are improving the early childhood system in Brownsville, Brooklyn."

Core to the creation of UB was the formation of a family advisory board (FAB), which is solely composed of parents and caregivers who live in Brownsville. Soon after the creation of the FAB, UB formed the provider action team (PAT), which is composed of the more traditional CI members, including, but not limited to, healthcare workers, nonprofit organizations, childcare providers, and the Brooklyn Public Library (BPL). UB also invited FAB members to attend this provider network as a way to ensure resident voices are well represented during

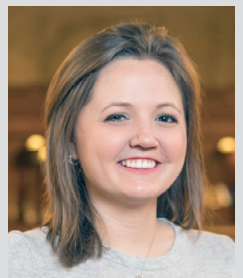

Kristen Rocha Aldrich is the Associate Program Director of Too Small to Fail (TSTF) at the Clinton Foundation. Prior to working with TSTF, she spent over five years at the New York Public Library creating and managing their early childhood education department. She is currently serving as a member of ALSC's Early Childhood Programs and Services committee and is Co-Chair of ALSC's Quicklists Consulting committee. 
collaborative planning activities. UB also has a leadership council (LC) of executives, professors, and field experts who are data driven and focused on supporting and advocating for the FAB and PAT. They support UB by working to troubleshoot bureaucratic barriers and other problems presented to them by the FAB and PAT, but the LC is not a decision-making group.

The FAB and PAT created three main projects in Brownsville to improve early childhood learning (focusing on ages birth to three years old):

1. Books for Brownsville, partially lead by BPL, is a serviceprovider training initiative inspired by Reach Out and Read, a national nonprofit that gives young children a foundation for success by incorporating books into pediatric care. Providers who participate in the trainings put the methods developed by Books for Brownsville into practice and distribute books and other family resources to the families they serve. The methods are developed so that providers can seamlessly integrate into their daily routines and will not ask them to do something completely new.

2. The Family Co-Op is a two-generational program for infants, toddlers, and their caregivers. It brings free, fun, educationally enriching weekend programming to underutilized spaces. It is inspired by work from Scholastic Education, the Yale Child Study Center, and the community of Grundy County (TN). The Family Co-Op is designed to build skills, reduce the isolation reported by many parents of young children, and counteract negative narratives by starting with the question, "What would you like to celebrate about Brownsville?"

3. Learning Landscapes implements the "Talking is Teaching" campaign of Too Small to Fail (TSTF), the early childhood initiative of the Clinton Foundation that promotes early brain and language development by supporting parents and caregivers with tools to talk, read, and sing with their young children from birth. UB creates toolkits using TSTF's early literacy and social emotional development resources, as well as co-creates Brownsville-specific resources that transform everyday places frequented by families from idle spaces into learning and bonding opportunities.

\section{References}

1. John Kania and Mark Kramer, “Collective Impact," Stanford Social Innovation Review (Winter 2011), accessed July 10, 2019, https://ssir.org/articles/entry/collective _impact.
UB will start by launching at two grocery stores in 2019 and look to expand and scale the project by permanently transforming larger structures such as bus stops into engaging, skill-building learning environments. As a Talking is Teaching community, the vision is that the neighborhood itself becomes a landscape for learning.

Through these three projects, UB forges a consensus between providers, residents, and field experts to create sustainable, positive change desired by community residents and providers. Although this approach to CI might take longer, it's intentionality cannot be matched, and it is this intentionality that will best serve the community members.

In your library branch's community, there is likely a CI project making decisions for your patrons. If you're not already involved, it is highly recommended you add your voice to the CI leaders. Not only is it a great way to continue supporting your patrons, it is also a forum for you to connect with other community organizations and residents to help co-solve problems and build connective tissue between organizations that may have been previously siloed.

As a public librarian, there are many ways for you to get involved, and all levels of involvement can make a positive impact. Here are a few ideas:

- Take on a leadership role in the group and help create programming for and by community residents.

- Attend the CI meetings and take notes to share with your patrons.

- Offer to host programs, focus groups and/or meetups at your location.

- Encourage your patrons to become active members of their local CI project.

- Get your CI group to start including residents in their meetings and leadership if they do not already.

- Do all of the above! \&

2. United for Brownsville, "How We Work," accessed July 31, 2019, www.unitedforbrownsville.org/how-we-work. 